See discussions, stats, and author profiles for this publication at: https://www.researchgate.net/publication/318923892

\title{
On patients, doctors and ethnographers: A response to Launer
}

Article in Postgraduate Medical Journal · August 2017

DOI: 10.1136/postgradmedj-2017-135203

2 authors:

Robert Power

Royal College of Surgeons in Ireland

7 PUBLICATIONS 3 CITATIONS

SEE PROFILE

Some of the authors of this publication are also working on these related projects:

Debating Authenticity View project

"New" Poverty in Celtic Tiger Ireland View project
A. Jamie Saris

National University of Ireland, Maynooth

41 PUBLICATIONS 218 CITATIONS

SEE PROFILE 


\section{On patients, doctors and ethnographers: a response to Launer}

\section{INTRODUCTION}

In a recent piece, John Launer calls for 'patient-led ethnography' because it 'could be a rich source of information for improving healthcare'. In the spirit of opening up a discussion regarding the value of ethnography for driving improvements in access to care, healthcare quality and patient safety, however, we would like to offer the following response to Launer. And in an effort to maintain consistency with Launer's article, we limit the references, with a few exceptions, to the same references he cites in 'Patients as ethnographers': namely, Leigh Goodson and Matt Vassar's (2011) 'An overview of ethnography in healthcare and medical education research', alongside Jan Savage's (2000) 'Ethnography and health care'. ${ }^{3}$

Launer's experience of ethnography occurs somewhat accidentally. During a 2-week hospital stay, he comes up with a playful idea to regard himself and his colleague 'not as patients but as undercover ethnographers, engaged to observe how a modern hospital ward functions'. In crucial respects, a doctor donning the garb of an ethnographer, even in play, marks an important moment in the increasing normalisation of this term in medical settings. Twenty years ago, that same doctor, with the same plan, might have needed 'ethnographer' explained to her. Yet, as Hunzinga reminds us, 'all play means something', and generally something significant. ${ }^{4}$ One of the things it means for Launer is a licence to see care from the other side, as it were, a perspective that highlights some of his own unspoken perceptions with which he operated as a medical practitioner, as well as some of the tacit rules by which a hospital ward actually operates. While this movement between the strange and the familiar is a classic anthropological insight, it obscures the central question that Launer accidentally poses: what makes someone an 'ethnographer' and/ or an insight, 'ethnographic'. Elaborating these ideas, we feel, will facilitate the movement of some of the insights in Launer's piece to framing ways to make the actual transformations in the structure and delivery of health services that his work shows are necessary.

\section{ETHNOGRAPHY AND THE ETHNOGRAPHIC}

Our first point is that ethnography is not just a technique/methodology, but more a collective name for three moments of an intellectual process that are to some degree logically separate but are usually found in some combination together: (1) a style of formulating research, (2) a method of knowing and revealing, and (3) a process of recording and communicating. Generally speaking, it is a combination of at least two of these moments that makes a piece of research or writing 'ethnographic'. Each moment of the process 'ethnography/ethnographic', moreover, has ethical, methodological and representational implications. What good ethnography reveals, then, is not just an observational insight into a world (a clinic, a village and so on), but more importantly the unspoken assumptions that (1) allow that world to cohere, and that (2) had to be learnt in order for someone to become a competent participant-observer within that setting, which reveals (3) that the ethnographer (as well as the reader) has different sets of meaningful assumptions that allow him/her to function as a competent social actor in other settings, but that such tacit understandings of the world are able to be translated (with greater or lesser success) into one another.

Here is where some of Launer's playfulness vitiates the promise of ethnography. Undercover ethnographer is an oxymoronic term that fundamentally undermines an ethnographic approach to research. Ethnography is fundamentally a collaborative practice where the ethnographer does not just observe participants: rather the ethnographer is a participant-observer working (generally dialogically) together with participants. In the Goodson and Vassar article cited by Launer, for example, ethnography involves 'intimate, face-toface interaction with participants' in order to present 'an accurate reflection of participant perspectives and behaviours'. Launer correctly views himself as an important research tool, but no ethnographer relies on just that one tool: participant perspectives are lacking in Launer's interpretation of his work, and (ironically, as a doctor) he is in a privileged position to gather them.

Ethnographers observing participants without their knowledge, then, is practically and ethically at odds with the logic of choosing an ethnographic approach. Knowledge comes not from the ethnographer per se, but, rather, from her collaboration with participants in the research process. To put that in slightly different terms, ethnography seeks to unpack participants' tacit knowledge about how they relate to each other in a variety of formal and informal settings, with the working assumption (not always born out) that this tacit knowledge is patterned. In order to unpack that tacit knowledge, the ethnographer must be an active participant observer talking to participants and trying to walk in another person's shoes, but only with permission, as it were. After an interview is transcribed, for example, participants are asked if they would like to see a copy of the transcription, which they are able to edit, delete or elaborate to ensure that the basis of the interpretation of their tacit knowledge is accurately represented. Some ethnographers go further and include participants in the preparation of manuscripts for publication. At all stages during ethnographic research, moreover, participants are reminded that they can withdraw from the research, withdraw aspects of their contributions, redact certain statements and/or challenge scholarly interpretations.

\section{LEARNING AN ECOLOGY OF CARE}

Nonetheless, Launer's 'striking observation' is an insightful one: that is, healthcare professionals, of all hues, dedicated a small amount of time conversing with patients, and the 'majority of such contacts were in fact with nursing assistants... or with domestic workers who were delivering meals or cleaning and tidying'. This statement certainly rings true to any ethnographer who has researched clinical settings. What makes an observation ethnographic, however, is the pursuit of the tacit and overt understanding explaining observations. It is broadly accepted, for example, that healthcare professionals, throughout the globe, are both busy and in short supply. Senior clinical staff do not necessarily deliver day-to-day care. Indeed, one could probably elicit some version of the following statement from most professional caregivers on the ward: doctors diagnose, nurses manage, nursing assistants deliver care and domestic workers deliver meals and tidy. What 'might surprise the staff', in Launer's phrasing, is how obvious that set of rules appears to patients and how sometimes unnecessary it also actually appears.

Launer further observes that '[s]tyles seemed independent of professional identity'. This observation is also interesting, as it suggests that professional identity (alongside the body of knowledge that makes a professional) is rigorously acquired and begs the questions 
how precisely it is taught. Here is where interacting with staff might have provided Launer-as-ethnographer a chance for a teaching-and-learning moment for Launer-as-doctor. Professionals develop under two curricular regimes: a formal and a tacit one, or, how it is sometimes put in the literature, 'taught' and a 'caught' forms of learning. ${ }^{5}{ }^{6}$ Professionals of all stripes are generally aware of such regimes of knowledge and many actually express discomfort with aspects of their learning. Of course, this learning does not end after certification, but continues through a series of power-laden interactions, such as mentorship and 'learning the ropes' in a new setting. A hospital ward, like any other human setting, becomes familiar, even habitual, for those most consistently associated with it. Ironically, it is often these habits that render the ward alienating, even uncomfortable, for practical interlopers, such as patients, even when they form the notional focus of the activities of the institution.

Interestingly, Launer notes that when 'staff engaged personably, we found that it enabled us to speak more fully of our lived experience of illness'. Moreover, personable communication helped in the development of 'more coherent accounts of what was happening in our own bodies'. In other words, talking to people in a personable manner seemed to be good healthcare but, for the most part, the conversational style used by most healthcare professionals 'constrained us to speak only in terms of physical symptoms, or in some cases not at all'. Here Launer engages with the crux of his experience that a more dialogical approach with other positions in an ecology of care might have helped him elaborate more explicitly. The hospital ward is, in part, a play into which patients are invited (unwillingly) and assigned parts on which they would probably would have liked to have been consulted beforehand. The other participants seem, at times, to play their roles with little sense of how much sense the performance makes to the supposed centre of the drama, and, worse, questions of scene, motivation and setting are generally unwelcome. All these could be put down to an unfortunate inconvenience, except for the fact that crucial information is potentially lost in more stilted encounters, and the sense of alienation of the focus of care inhibits the actual goals of the ward.

\section{ETHNOGRAPHER KNOW THYSELF}

A lack of dialogical engagement with participants, however, leads to a lack of a central part of Launer's project: the realisation that there is no such thing as a view from nowhere, and that one's perspective bears the mark of historical processes and subject-markers (gender, seniority, professional identity and the like) that facilitate some observations and interpretations while occluding others. Launer, for example, finds senior doctors as detailed and unhurried, while junior doctors were able to supply only fragmentary information. A lack of contact between senior doctors and patients, which Launer observes, for example, then has some significant implications for patient care, and begs the question 'why?' On the other hand, contact between nursing assistants, domestic workers and patients seems much easier, but is still insulated from those with more authority on the ward. A doctor-patient-ethnographer as opposed to a lay-patient-ethnographer has scope to ask questions and reflect on practices in a privileged fashion, an opportunity not taken advantage of in this piece.

Finally, Launer notes that his 'imaginary research study was brief, highly selective, and had many obvious limitations, including the fact that we were both known by almost everyone to be doctors'. By definition, the qualitative character of ethnography contains limitations. Nonetheless, patterns are revealed through ethnographic constitution of the problem, collaborative ethnographic methods and ethnographic descriptive integration that are opaque to other methods. At its core, ethnography aims to explore and understand people and their practices in the world, revealing patterns of action and belief that are not obvious to observers or participants in the initial phases of the work. Ethnography places specific emphasise on demystifying categories within institutions and rebalancing hierarchical classifications of people. In doing so, ethnographers unpack non-linear, often messy, contested and frequently ambiguous interpretations of people and their organisational/professional practices, philosophies and ideologies. But as this complexity is iteratively unpacked, potential and possible pathways towards suitable, usable and workable solutions to pressing issues reveal themselves.

\section{CONCLUSION: KNOWING ONE'S HABITS (AND POTENTIALLY LEARNING NEW ONES)}

To his credit, Launer, in a brief period of time, uncovers significant issues on the ward, fissures into which potentially important clinical information can disappear, alongside types of sociolinguistic framing and institutional hierarchies that form obvious stumbling blocks to implementing patient-centred care. These findings have non-trivial quality and patient safety implications. Indeed, they are precisely the kind of work in what UX Design researchers call 'problem-space', labour that is necessary to do before intelligent questions can even be asked, never mind various 'consultants' being brought in to propose 'solutions'. Launer also provides convincing evidence that habitual ways of managing and delivering care make problems for all concerned, underscoring the now-venerable observation in the field that revealing and altering habits is the key to enhancing the quality and safety in healthcare. ${ }^{78} \mathrm{We}$ await the fusion of Launer-as-doctor and Launer-as-more-developed-ethnographer for a more complete and collaborative analysis of patient care and workable pathways to its improvement.

\section{Robert Power, ${ }^{1}$ A Jamie Saris ${ }^{2}$}

${ }^{1}$ Office of Research and Innovation, Royal College of Surgeons in Ireland, Dublin, Ireland

${ }^{2}$ Department of Anthropology, National University of Ireland Maynooth, Maynooth, Ireland

Correspondence to Dr A Jamie Saris, Department of Anthropology, National University of Ireland Maynooth, Newtown Road, Collegeland, Maynooth, Ireland; Ajamie.Saris@nuim.ie

Contributors RP is a postdoctoral researcher at the Royal College of Surgeons in Ireland. AJS is a senior lecturer in anthropology at Maynooth University, Ireland. Both authors contributed equally to this letter.

\section{Competing interests None declared.}

Provenance and peer review Not commissioned; internally peer reviewed.

(c) Article author(s) (or their employer(s) unless otherwise stated in the text of the article) 2017. All rights reserved. No commercial use is permitted unless otherwise expressly granted.

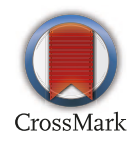

To cite Power R, Saris AJ. Postgrad Med J Published Online First: [please include Day Month Year]. doi:10.1136/postgradmedj-2017-135203

Accepted 14 July 2017

Postgrad Med J 2017;0:1-3.

doi:10.1136/postgradmedj-2017-135203

\section{REFERENCES}

1 Launer J. Patients as ethnographers. Postgrad Med 2017;93:371-2.

2 Goodson L, Vassar M. An overview of ethnography in healthcare and medical education research. J Educ Eval Health Prof 2011;8:4.

3 Savage J. Ethnography and health care. BMJ 2000;321:1400-2. 
4 Huizinga J. Homo ludens. London: Beacon Press Books, 1950.

5 Cruess RL, Cruess SR, Boudreau JD, et al. Reframing medical education to support professional identity formation. Acad Med 2014;89:1446-51.
6 Cruess RL, Cruess SR, Boudreau JD, et al. A schematic representation of the professional identity formation and socialization of medical students and residents: a guide for medical educators. Acad Med 2015;90:718-25.
7 Galbraith RM, Holtman MC, Clyman SG. Use of assessment to reinforce patient safety as a habit. Qual Saf Health Care 2006;15(Suppl 1):i30-3.

8 Vogus TJ, Hilligoss B. The underappreciated role of habit in highly reliable healthcare. BMJ Qual Saf 2016:25:141-6. 